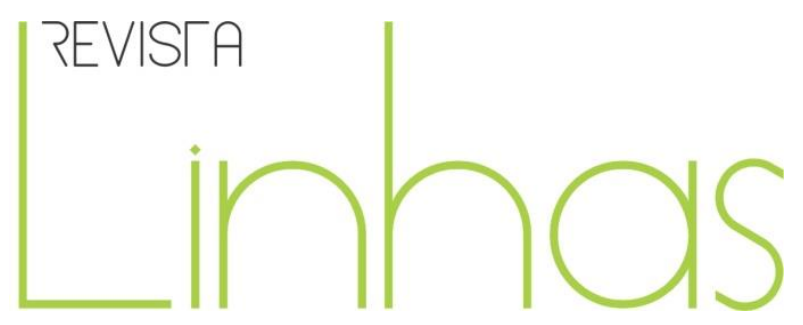

\title{
Políticas públicas e produção de um contexto brasileiro para a formação continuada de professores no período de 2003 a $2015^{1}$
}

\begin{abstract}
Resumo
O artigo apresenta um estudo sobre os programas de formação inicial e continuada de professores, no período de 2003 a 2015. Em nível nacional, essa formação tem sido promovida por políticas públicas educacionais desenvolvidas pelo Ministério da Educação e Cultura (MEC) e pela Coordenação de Aperfeiçoamento de Pessoal de Nível Superior (Capes). O objetivo foi conhecer o contexto brasileiro de produção de políticas para a formação de professores, com um olhar mais atento para a formação continuada, cuja oferta aumentou consideravelmente no período pesquisado, em consonância com as Diretrizes Curriculares Nacionais para Formação de Professores (DCNFP). A pesquisa em documentos disponibilizados em sites oficiais - Portal do MEC e Portal da Capes - possibilitou obter informações sobre esses programas e mostrou um conjunto de políticas, postas em ação por Instituições de Ensino Superior. Além disso, a produção acadêmica sobre esses programas proporcionou desenhar um panorama de seus efeitos, sendo uma forma de dar visibilidade às finalidades em função do público a quem se dirigem. A partir do conceito de desenvolvimento profissional, embasado em Imbernón (2009), Gatti (2008), Gatti e Barreto (2009), Nóvoa (2009) e Formosinho (2009), considera-se que alguns programas têm maior aproximação com o que os autores compreendem do que outros, que teriam um papel de capacitação, ressignificando o desempenho dos professores em sala de aula, em relação às metodologias e conteúdos didáticos, mas em caráter pontual e situado em dado momento, talvez por serem de curta duração e, sem previsão de continuidade, teriam menor potencial para o desenvolvimento profissional.
\end{abstract}

Palavras-chave: Formação. Professores. Desenvolvimento Profissional.

\section{Para citar este artigo:}

DIAS, Lisete Funari; FERREIRA, Maira. Políticas públicas e produção de um contexto brasileiro para a formação continuada de professores no período de 2003 a 2015. Revista Linhas. Florianópolis, v. 18, n. 38, p. 344-374, set./dez. 2017.

\footnotetext{
${ }^{1}$ Este artigo foi desenvolvido no Programa de Pós-Graduação em Educação em Ciências: Química da Vida e Saúde, da Universidade Federal do Rio Grande do Sul, onde Lisete Funari Dias é doutoranda e Maira Ferreira é Professora Pesquisadora e Colaboradora do Programa.
} 


\title{
Public policies and production of a Brazilian context for the continuing education of teachers in the period from 2003 to 2015
}

\begin{abstract}
This article presents a study about programs for initial and continuing education of teachers, from 2003 to 2015. This teacher education has been promoted on a national level by public education policies developed by the Ministry of Education and Culture (MEC) and by CAPES, the Coordination for the Improvement of Higher Level Personnel. The objective was to understand the Brazilian context in which teacher education policies are produced, with a greater focus on continuing education, the provision of which increased considerably in the period studied, in keeping with the National Curricular Guidelines for Teacher Education (DCNFP). The study of documents found on the MEC and CAPES websites provided information about these programs and revealed a set of policies placed in action by the institutions of higher education. Moreover, the review of academic studies on these programs allowed sketching an overview of their effects, which is a way to give visibility to the finalities according to the public at which they are aimed. Using the concept of professional development, based on Imbernón (2009), Gatti (2008), Gatti and Barreto (2009), Nóvoa (2009) and Formosinho (2009), it was found that some programs have greater approximation with the understanding of these authors than others, and that these programs had a role in teacher training, helping to redefine the classroom performance of teachers in relation to didactic methodologies and contents, but only in specific occasions and circumstances; perhaps because of their short term nature, and because a continuation is not foreseen, they would have less potential for the professional development.
\end{abstract}

Keywords: Education. Teachers. Professional Development. 


\section{Introdução}

Em atendimento às políticas públicas de educação, desde o início do século XXI, a formação continuada de professores está na pauta como uma das prioridades para alcance das metas estipuladas pelo Plano Nacional da Educação (PNE) em suas diferentes edições. No PNE (2014-2024), a meta 16 se refere à formação de 50\% dos professores da educação básica em nível de pós-graduação e a garantia de formação continuada a todos os profissionais da educação básica (BRASIL, 2014).

Em nível nacional, essa formação tem sido promovida por políticas públicas educacionais desenvolvidas pelo Ministério da Educação e Cultura (MEC) e pela Coordenação de Aperfeiçoamento de Pessoal de Nível Superior (Capes) que, desde 2007, assumiu a responsabilidade de subsidiar o MEC na formulação de políticas para a formação inicial e continuada de profissionais que atuam na educação básica (KUENZER, 2011). As ações de formação, contemplando as escolas de educação básica, são desenvolvidas pelas universidades, em cursos articulados aos projetos de extensão e/ou aos cursos de graduação ou pós-graduação.

Considera-se que o contexto educacional brasileiro é tecido com as exigências das reformas curriculares, indicadas pelas Diretrizes Curriculares Nacionais para Educação Básica (DCNEB) (BRASIL. MEC, 2013a) e, especialmente, pelo anúncio, no ano de 2015, de uma Base Nacional Comum Curricular (BNCC). Também, as Diretrizes Curriculares Nacionais para a Formação de Professores (DCNFP) (BRASIL. MEC, 2015C) apontam orientações para mudanças curriculares em cursos de formação inicial de professores, bem como, orientam para a proposição de ações de formação continuada. Em meio à emergência de diferentes políticas públicas curriculares, a formação de professores e o papel da docência têm sido recorrentemente referidos como fundamentais para que as mudanças propostas ocorram.

Assim, a formação de professores passou a ser considerada estratégica para a implementação de mudanças na educação básica, ampliando a produção de políticas públicas voltadas para a melhoria da formação inicial e, especialmente, para a formação de professores em exercício. Tais políticas vêm implementando muitos programas de 
formação e torna-se importante conhecê-los, a fim de entender as características e o contexto em que foram criados e desenvolvidos.

Além disso, o incentivo à formação de professores pode ser evidenciado no texto das atuais DCNFP (BRASIL. MEC, 2015C), quando em seu Art $1^{\circ}$, parágrafo $2^{\circ}$, aponta que a formação inicial e continuada de professores da educação básica deve atender as políticas de educação, à luz das "Diretrizes Curriculares Nacionais e ao padrão de qualidade e ao Sistema Nacional de Avaliação da Educação Superior (Sinaes)" (BRASIL. MEC, 2015c, p.2).

A partir dessas considerações, apresenta-se um estudo sobre os programas de formação inicial e continuada de professores, no período de 2003 a 2015, visando mostrar o contexto brasileiro de produção de políticas públicas para a formação de professores, com um olhar mais atento para a formação continuada.

A pesquisa, realizada em documentos disponibilizados em sites oficiais, como o Portal do MEC (http://portal.mec.gov.br/formacao) e o Portal da Capes (http://www.capes.gov.br/educacao-basica), possibilitou a obtenção de informações sobre tais programas de formação, sobre as finalidades previstas, o público envolvido e as ações planejadas, bem como a organização, duração e resultados relacionados ao número de editais e profissionais atendidos.

\section{Formação continuada de professores como objeto de estudo}

Ao tratar sobre políticas educacionais no Brasil, em específico as relacionadas à formação continuada de professores, considera-se pertinente lembrar que seus parâmetros e modelos são ditados por modelos internacionais, com financiamento de organizações internacionais (para os países mais pobres), estando entre elas o Fundo Monetário Internacional (FMI) e o Banco Mundial (BM), cujo propósito é emprestar dinheiro para apoiar projetos de desenvolvimento, em particular na educação (CHARLOT, 2013).

Segundo Gatti (2008), as políticas públicas e suas ações seguem na direção de reformas curriculares e de mudanças na formação dos docentes, como exercendo o importante papel de formadores das novas gerações. Para a autora, essas organizações 
internacionais ditam os modelos, a exemplo dos que podem ser encontrados em documentos do BM (1996).

No documento do BM (1996) é ressaltado que a formação em serviço é uma das maneiras mais eficientes para aumentar o desempenho dos alunos, quando comparada à redução do tamanho das turmas ou fornecimento de materiais de leitura complementar. Ainda, o BM sugere a formação contínua de professores na modalidade a distância por ser uma fonte de economia e permitir ao professor continuar em serviço (BANCO MUNDIAL, 1996).

Gatti (2008) aponta que nesses documentos é sinalizada a ideia de que os professores não estão preparados para formar as novas gerações para uma "nova" economia mundial, por isso, haveria a necessidade de melhorar a sua formação. Para o pesquisador espanhol Imbernón (2009, p. 23), as mudanças sociais orientam o caminho da formação permanente e afirma que "ninguém deve duvidar de que qualquer reforma da estrutura e do currículo do sistema educativo e sua inovação quantitativa ou qualitativa - sobretudo nesta última - deve contar com o apoio do professorado". No entanto, refere-se que em qualquer transformação educativa, os professores não devem visar somente ao aperfeiçoamento de seus alunos e do sistema educativo, mas também a sua formação e seu desenvolvimento profissional.

Segundo Imbernón (2009), para mudar a educação é necessário promover mudanças no professor, mas também no contexto da escola, porque este pode limitar ou impossibilitar a efetivação da inovação. Além disso, considera que se deva dar a palavra aos professsores, tornando-os protagonistas de sua própria formação e dos projetos de mudança na escola, que devem constituir-se como foco no processo de ação-reflexãoação para alcance de melhoria e desenvolvimento. Para o autor, uma formação na própria instituição educativa, baseada em situações do contexto e problemas práticos definidos por suas necessidades, com projetos ou pesquisas-ações, supera outras modalidades formativas de treinamento.

Por outro lado, mesmo com essas justificativas, considera que esse tipo de formação possa gerar resistência nos professores, mas que será em grau maior se for uma imposição aleatória, descontextualizada e pouco útil, como ele caracteriza a formação nos moldes de treinamento. Explica que, neste modelo, o formador seleciona 
as atividades com ações generalizadoras, supondo que ajudarão os professores no alcance da aprendizagem dos alunos. São exemplos de treinamento, cursos, seminários, oficinas, todos dirigidos por especialistas ou transmitidos verticalmente por um "expert solucionador de problemas" (IMBERNÓN, 2009, p. 51).

Na perspectiva de caracterizar diferentes modelos de formação, o pesquisador português Formosinho (2009) diferencia formação contínua e desenvolvimento profissional em uma mesma realidade. Para ele, o "desenvolvimento profissional é um processo mais vivencial e mais integrador do que a formação contínua. Não é um processo individual, mas um processo em contexto" (FORMOSINHO, 2009, p. 225).

Ao referir-se à educação permanente de professores, o autor reconhece a formação contínua como sendo um processo de ensino/formação, enquanto o desenvolvimento profissional como sendo um processo de aprendizagem/crescimento. Nesse sentido, é importante considerar que, quanto maior o tempo de ensino/formação, maiores as possibilidades de resultar em aprendizagem/desenvolvimento dos professores.

O tempo aparece como fator importante para o desenvolvimento profissional dos docentes e o autor, ao comentar as pesquisas em Portugal sobre a formação de professores, enfatiza que o modelo de cursos de formação de curta duração está desacreditado como instrumento de desenvolvimento profissional. Afirma que, de modo geral, esses cursos são ministrados independentes do contexto de trabalho dos professores e de suas necessidades reais. Ainda, para esse autor, "a formação pósgraduada e especializada, por demandar uma carga horária maior para estudo e reflexões, por ser de escolha livre do professor, pode ser entendida como desenvolvimento profissional" (FORMOSINHO, 2009, p. 248).

De modo semelhante, para Gatti e Barreto (2009), a formação de professores deve acontecer em um contínuo, ao longo da vida profissional, entendendo esse tipo de formação como desenvolvimento profissional. Também Nóvoa (2009, p.20), ao se referir à formação de professores em serviço, afirma que a reflexão coletiva dos docentes "dá sentido ao seu desenvolvimento profissional”, mas destaca a importância em considerar as condições existentes nas escolas e as políticas públicas relacionadas aos professores, uma vez que: 
[...] seria inútil apelar à reflexão se não houver uma organização das escolas que a facilite. É inútil reivindicar uma formação mútua, interpares, colaborativa, se a definição das carreiras docentes não for coerente com este propósito. É inútil propor uma qualificação baseada na investigação e parcerias entre escolas e instituições universitárias se os normativos legais persistirem em dificultar esta aproximação. (NÓVOA, 2009, p. 20)

Com essas reflexões e considerando os pressupostos teóricos apontados pelos autores, foram analisados cursos e ações desenvolvidas pelas políticas públicas de formação, procurando compreender a formação continuada de professores e o papel dela para o seu desenvolvimento profissional.

\section{Políticas e ações de formação continuada em programas, planos, projetos, cursos e pactos}

A implementação de ações de formação continuada de professores, como já dito, tem sido uma demanda das discussões sobre a necessidade de melhoria da educação básica, sendo possível encontrar uma gama de programas implementados nas escolas pelo MEC e Capes.

No Portal do MEC há um link intitulado Portal do Professor (disponível em http://portal.mec.gov.br/portal-do-professor) que, instituído em 2008, oferece aos professores, mediante cadastro, acesso a sugestões de aulas para diferentes disciplinas e áreas de conhecimento, recursos tais como, vídeos, fotos, mapas, áudio e textos, além de informações sobre a legislação específica educacional e sobre cursos de formação de professores oferecidos em nível municipal, estadual e federal.

Na pesquisa realizada no Portal do MEC, ano de 2015 (BRASIL. MEC, 2015b), na aba formação de professores, encontramos registrados os seguintes programas de formação: Rede Nacional de Formação Continuada de Professores, Programa Gestão da Aprendizagem Escolar (Gestar II), Pró Letramento, Programa Nacional de Formação Continuada em Tecnologia Educacional (Proinfo Integrado), Ambiente Colaborativo de Aprendizagem (e-Proinfo), Pró Infantil, Pacto Nacional pela Alfabetização na Idade Certa (Pnaic) e o Plano Nacional de Formação de Professores da Educação Básica (Parfor), nas modalidades presencial e a distância. O Pacto pelo Fortalecimento do Ensino Médio 
(Pnem) encontra-se no link (http://pactoensinomedio.mec.gov.br/). Ainda relacionado às Tecnologias da Informação e Comunicação (TICs), o Projeto Um Computador por Aluno (UCA), com aquisição de laptops por meio do Programa Um Computador por Aluno (Prouca), encontra-se no link (http://www.fnde.gov.br/programas/programa-nacional-detecnologia-educacional-proinfo/proinfo-programa-um-computador-por-aluno-prouca).

Também no Portal do MEC, no link (http://portal.mec.gov.br/secretaria-deeducacao-continuada-alfabetizacao-diversidade-e-inclusao/apresentacao) da Secretaria da Educação Continuada, Alfabetização e Diversidade e Inclusão (Secadi/MEC), há informações de políticas públicas integradas aos Programas e Ações da Educação Superior, Profissional e Tecnológica e Básica. A Secadi tem implementado programas destinados à formação de gestores e educadores, à produção e distribuição de materiais didáticos e pedagógicos, à disponibilização de recursos tecnológicos e à melhoria da infraestrutura das escolas, buscando incidir sobre fatores que promovam o pleno acesso à escolarização e à participação de todos os estudantes, com redução das desigualdades educacionais, com equidade e respeito às diferenças (BRASIL. MEC, 2013b; CAPES, 2013b).

Para atender demandas desses grupos, são consideradas as seguintes temáticas: Educação Especial, Educação para as Relações Étnico-Raciais, Educação do Campo, Educação Escolar Indígena, Educação Quilombola, Educação em Direitos Humanos, Educação Inclusiva, Gênero e Diversidade Sexual, Combate à Violência, Educação Ambiental e Educação de Jovens e Adultos. Nessa perspectiva, ainda no Portal do MEC, encontram-se links de acesso a informações sobre os Programas Prolind (Programa de Apoio à Formação Superior para Professores que atuam em Escolas Indígenas), Procampo (Programa de Apoio à Formação Superior em Educação do Campo) e Programa de Formação Continuada de Professores na Educação Especial (BRASIL. MEC, 2013b).

No Portal da Capes, no link Formação de Professores da Educação Básica, são disponibilizadas informações sobre os programas de formação para professores que, por meio da Diretoria de Formação de Professores da Educação Básica Presencial (DEB) e a Distância (DED), ofertam vagas em cursos de licenciatura presenciais e a distância, com fomento a projetos de estudos, pesquisas e no desenvolvimento de programas para a valorização do magistério (CAPES, 2015). O Decreto n 6755, de 29 de janeiro de 2009 
(BRASIL, 2009), institui a Política Nacional de Formação de Profissionais do Magistério da Educação Básica, disciplinando a atuação da Capes no fomento aos programas de formação inicial e continuada, sendo neste Portal, encontrados registros dos seguintes programas de formação: Programa de Consolidação das Licenciaturas (Prodocência), Programa Institucional de Bolsas de Iniciação à Docência (Pibid), Observatório da Educação (Obeduc), Programa Novos Talentos, Programa de Apoio a Laboratórios Interdisciplinares de Formação de Educadores (Life) e Universidade Aberta do Brasil (UAB). Fazendo parte de uma das linhas de ação da Capes, indução e fomento da formação inicial e continuada de professores para educação básica (presencial e a distância), encontra-se no Portal, o Plano Nacional de Formação de Professores da Educação Básica (Parfor), também encontrado no Portal do MEC, assim como o acesso à Plataforma Freire.

A partir da pesquisa nos portais (MEC e Capes), apresenta-se, no Quadro 1, uma síntese dos programas/cursos de formação de professores, abrangendo a formação inicial e continuada e apenas formação continuada, no período de 2003 a 2015.

Quadro 1: Programas para formação de Professores (concessão de Bolsas*; fomento**)

\begin{tabular}{|c|c|c|}
\hline Programa/cursos & Inicio/Final & Público \\
\hline \multicolumn{3}{|c|}{ Formação inicial e continuada } \\
\hline $\begin{array}{l}\text { 1-Prolind ** } \\
\text { (MEC/Secadi/SESU/FNDE) }\end{array}$ & $2005 /$ & Professor indígena em serviço ou população indígen \\
\hline $\begin{array}{l}\text { 2-UAB ** } \\
\text { (MEC/Capes) }\end{array}$ & $2006 /$ & $\begin{array}{l}\text { Professores em Serviço; População distante dos } \\
\text { centros de formação }\end{array}$ \\
\hline $\begin{array}{l}\text { 3-Obeduc */** } \\
\text { (MEC/Capes Secadi/INEP) }\end{array}$ & $2006 /$ & $\begin{array}{l}\text { Alunos de licenciatura e de pós-graduação stricto } \\
\text { sensu }\end{array}$ \\
\hline $\begin{array}{l}\text { 4-Pibid */** } \\
\text { (MEC/Capes) }\end{array}$ & $2007 \mid$ & Alunos de licenciaturas presenciais \\
\hline $\begin{array}{l}\text { 5- Procampo ** } \\
\text { (MEC/Secadi/SESU/FNDE) }\end{array}$ & $2007 \mid$ & $\begin{array}{l}\text { Professores que atuam em escolas do campo, } \\
\text { população do campo e quilombola }\end{array}$ \\
\hline $\begin{array}{l}\text { 6-Prodocência ** } \\
\text { (Capes) }\end{array}$ & $2008 /$ & $\begin{array}{l}\text { Professores das IES públicas e estudantes de } \\
\text { cursos de licenciatura }\end{array}$ \\
\hline $\begin{array}{l}\text { 7- Parfor ** } \\
\text { (Capes) }\end{array}$ & $2009 /$ & Professores atuantes na educação básica pública \\
\hline $\begin{array}{l}\text { 8-Novos Talentos ** } \\
\text { (Capes) }\end{array}$ & $2010 /$ & Professores e alunos das escolas de Educação Básica \\
\hline $\begin{array}{l}\text { 9- Life ** } \\
\text { (Capes) }\end{array}$ & $2012 /$ & $\begin{array}{l}\text { Licenciandos e professores atuantes nas } \\
\text { Instituições Públicas da Educação Superior (IPES) }\end{array}$ \\
\hline \multicolumn{3}{|c|}{ Formação continuada } \\
\hline $\begin{array}{l}\text { 1-Rede Nacional ** } \\
(\mathrm{MEC})\end{array}$ & $2003 /$ & Professores de educação básica \\
\hline $\begin{array}{l}\text { 2-Pró letramento * / ** } \\
\text { (MEC/Rede Nacional) }\end{array}$ & $2005 / 2012$ & $\begin{array}{l}\text { Professores de anos iniciais do Ensino } \\
\text { Fundamental }\end{array}$ \\
\hline
\end{tabular}




\begin{tabular}{|l|c|l|}
\hline $\begin{array}{l}\text { 3-Prólnfantil * } \\
\text { (MEC/Rede Nacional) }\end{array}$ & $2005 / 2011$ & $\begin{array}{l}\text { Profissionais que atuam em educação infantil, nas } \\
\text { creches e pré-escolas das redes públicas }\end{array}$ \\
\hline $\begin{array}{l}\text { 4-Programa de } \\
\text { Educação Especial ** } \\
\text { (MEC/Secadi) }\end{array}$ & $2007 / 2013$ & Professores da Educação Básica \\
\hline $\begin{array}{l}\text { 5-Gestar II ** } \\
\text { (MEC/Rede Nacional) }\end{array}$ & $2007 / 2013$ & $\begin{array}{l}\text { Professores de língua portuguesa e matemática } \\
\text { dos anos finais do Ensino Fundamental }\end{array}$ \\
\hline $\begin{array}{l}\text { 6-Proinfo Integrado ** } \\
\text { (MEC) }\end{array}$ & $2007 / 2013$ & $\begin{array}{l}\text { Professores e gestores de escolas públicas, } \\
\text { técnicos e demais agentes educacionais }\end{array}$ \\
\hline $\begin{array}{l}\text { 7-Portal do Professor } \\
\text { (MEC) }\end{array}$ & $2008 /$ & $\begin{array}{l}\text { Professores e gestores de Escolas Públicas de } \\
\text { educação básica }\end{array}$ \\
\hline $\begin{array}{l}\text { 8- UCA e Prouca ** } \\
\text { (MEC/FNDE/CNPq/ Capes) }\end{array}$ & $2010 / 2014$ & $\begin{array}{l}\text { Alunos e professores de escolas públicas de } \\
\text { educação básica }\end{array}$ \\
\hline $\begin{array}{l}\text { 9- Pnaic * / * } \\
\text { (MEC/FNDE) }\end{array}$ & $2013 / 2015$ & $\begin{array}{l}\text { Professores alfabetizadores e área da matemática } \\
\text { dos anos iniciais do Ensino Fundamental }\end{array}$ \\
\hline $\begin{array}{l}\text { 10- Pnem * ** } \\
\text { (MEC/FNDE) }\end{array}$ & $2014 / 2015$ & $\begin{array}{l}\text { Professores e coordenadores pedagógicos - } \\
\text { Ensino Médio não profissionalizante }\end{array}$ \\
\hline
\end{tabular}

Fonte: Portal MEC e Portal Capes (2015).

\section{O contexto dos programas de formação inicial e continuada no Brasil}

$O$ resultado da pesquisa, que teve por finalidade apresentar o contexto da formação continuada no Brasil, no período de 2003 a 2015, passou pela análise de 19 programas/cursos, sendo organizados em dois blocos: formação inicial e continuada e, apenas, formação continuada.

Da pesquisa, obteve-se um panorama e apresentam-se, a seguir, as finalidades, ações dos programas implementados, considerando sua abrangência e tempo de execução, de modo a ser possível vislumbrar a produção de um contexto para a formação inicial e continuada de professores no Brasil, nesse período. A partir daí, procurou-se ver os efeitos desses programas e o modo como podem ser considerados quanto às possibilidades de promover o desenvolvimento profissional dos sujeitos envolvidos.

\section{- Programas de formação inicial e continuada}

A seguir, dá-se destaque a alguns programas, tais como Pibid, Prolind, UAB, Procampo e Parfor, considerando aqueles que têm maior abrangência e/ou maior tempo para seu desenvolvimento.

O Programa Pibid, com recursos da Capes para custeio de materiais de consumo e de bolsas para licenciandos, professores da educação básica e da universidade, tem por 
finalidade incentivar a escolha pela licenciatura, valorizar o magistério, elevar a qualidade da formação inicial de professores e contribuir para a articulação entre teoria e prática (CAPES, 2013a; 2013d).

O Pibid, em vigência desde 2007, tem anúncio de continuidade, com o lançamento de um novo edital no ano de 2016. É um programa considerado de longa duração, levando-se em conta os editais vigentes até 2015, com bolsas concedidas em projetos com duração de até 48 meses. Segundo Relatório de Gestão da DEB (2009-2014), entre 2009 e 2014, foram concedidas 115.642 bolsas de estudo (CAPES, 2015).

Se considerarmos o tempo de duração e a continuidade prevista para as ações do Pibid, poderíamos vê-lo como processo de formação que contribui para o desenvolvimento profissional dos professores em exercício na educação básica e no ensino superior. Gatti e Barreto (2009) entendem que tal desenvolvimento depende da continuidade das ações que deve acontecer ao longo da vida profissional. Ainda, Formosinho (2009) considera que, quanto maior o tempo de ensino/formação maiores as chances de resultar em aprendizagens e desenvolvimento em sua área.

Com um olhar voltado para formação continuada de professores e de seu desenvolvimento profissional, resultados de pesquisas sobre o Pibid apontam que o estímulo financeiro para participação em eventos promoveu, tanto nos professores participantes como supervisores do Pibid, uma nova visão sobre a profissão, incentivando-os a cursarem mestrado, especialmente os mestrados profissionais (CORREA, 2014). Assim, o Pibid, ao fortalecer a relação entre teoria e prática docente, a pesquisa e a diversidade, estaria contribuindo para o desenvolvimento profissional dos professores em serviço (MARTELET, 2015).

Para Deimling (2014), o Pibid é imprescindível no processo de formação dos licenciandos, supevisores e coordenadores de área, tanto para atuação docente, quanto para a qualidade de todo o processo de formação. Também Silva (2015) considera a importância do programa para a formação dos professores da universidade (coordenadores de área) e dos professores da educação básica (supervisores de escolas), especialmente pelo exercício de um trabalho colaborativo entre ambos. 
Os resultados dessas pesquisas mostram que o Pibid tem sido considerado uma referência na formação inicial e continuada de professores, pois o envolvimento dos supervisores de escola e coordenadores de área, com o projeto, indica contribuições para o desenvolvimento profissional de professores em exercício. Tal constatação pode ser embasada nas teorizações de Formosinho (2009), que se refere ao processo contínuo de melhoria das práticas docentes, centrado no professor, com preocupação no benefício aos alunos como uma forma de desenvolvimento profissional.

Também, os programas Prolind, UAB, Procampo, Obeduc, Prodocência, Parfor, Novos Talentos e Life, todos vigentes em 2015, atuam na formação inicial e continuada de professores e têm como ponto de intersecção, a articulação com a educação básica. Alguns desses são voltados à criação e oferta de vagas em cursos de licenciatura para professores sem formação nas áreas em que atuam, tais como os programas Prolind, UAB, Procampo e Parfor, visando ainda atender políticas educacionais de inclusão ou expansão e de interiorização das universidades.

No caso da UAB, de acordo com o Relatório de Gestão Consolidado do MEC 20122014 (BRASIL. MEC, 2014C), desde 2010, o programa formou cerca de 120 mil professores na modalidade a distância, em cursos de primeira, segunda licenciatura e de pósgraduação. Neste mesmo relatório, Gatti et al (2011) apresentam dados de pesquisa apontando que, de 2006 até 2011, a UAB ofereceu cerca de 300 cursos de formação continuada.

O processo de formação proposto pela UAB contempla a formação inicial, considerando que muitos professores fazem um primeiro curso de licenciatura, mas, por outro lado, são professores em exercício, caracterizando-se por uma ação de formação continuada com baixo investimento para formar um grande contingente de docentes, especialmente considerando que os cursos são a distância.

Formar docentes em cursos da modalidade a distância amplia o espaço de formação docente, tanto para os formadores, quanto para os professores em exercício que cursam licenciatura. O que é esperado, mas nem sempre se confirma, é o fato de que nesse tipo de política de formação, os professores, além de terem formação na área de conhecimento na qual atuam, passem a fazer uso de maior número de ferramentas tecnológicas em suas aulas. Além disso, é esperado que obtivessem maior participação 
dos alunos nas atividades e que utilizem metodologias ativas, com aulas mais dinâmicas e interativas, aumentando os canais de comunicação com seus alunos e diversificando as formas de avaliação. Nesse processo, se espera para esse professor, a melhoria da escrita e da leitura, levando-o a aprimorar seu estudo de forma mais independente (MARTINS, 2015; BRANCO, 2014).

A utilização das tecnologias na educação é uma das transformações recentes pelas quais o mundo tem passado e tem impacto nas políticas educacionais e na proposição de ações, como é o caso da UAB. O uso de ferramentas da Educação a Distância (EaD), além de possibilitar a realização de cursos de atualização, propicia o acesso e discussão de conhecimento pedagógico, a partir de práticas com as TICS (IMBERNÓN, 2009). Nesse sentido, a UAB pode vir a constituir redes colaborativas na formação continuada de professores, como aconteceu com a implementação da Política Nacional de Educação Especial na perspectiva da Educação Inclusiva (BRASIL. MEC, 2008), pois, na modalidade a distância e explorando recursos da web, o curso possibilitou a formação de um grande número de professores para o Atendimento Educacional Especializado (AEE), em todo o território nacional (ROPOLI, 2014).

Semelhante à proposição da UAB, o Parfor também vem formando professores, em cursos presenciais e a distância, sendo que até o ano de 2013, 12 mil professores haviam concluído seus cursos de primeira licenciatura, segunda licenciatura e de formação pedagógica. Segundo o Censo da Capes, no ano de 2014, cerca de 50 mil professores cursaram algum curso de licenciatura ou curso de formação pedagógica (BRASIL. MEC, 2014C). De acordo com o Portal da Capes, o Parfor cumpre a sua finalidade, uma vez que os cursos estariam atraindo um grande número de professores sem a devida formação para as áreas em que lecionam, sendo esse um aspecto que consideram positivo para a continuidade do programa.

Pesquisas sobre o Parfor indicam que os professores, ao fazerem a livre escolha de realizar os cursos, sejam de primeira ou segunda licenciatura, ou ainda de formação pedagógica, estão reconhecendo a necessidade de formação para o exercício da profissão docente, percebendo a incompletude da sua (não) formação e a necessidade da busca de novos saberes (SANTOS, 2013; AMORIM, 2013). 
O Parfor, que atende tanto a formação inicial quanto a formação continuada, assim como outros que mencionamos, UAB, Prolind e Procampo, ocorrem em um tempo maior e possibilitam aos professores pensar em práticas, executar e analisar seu ensino e pensar alternativas didático-pedagógicas que oportunizam o seu desenvolvimento profissional. Conforme relatório elaborado pela professora Bernardete Gatti, em 2012, por solicitação da Capes, o Parfor tem destaque como uma experiência positiva, que está relacionada ao fato de o programa estar despertando nos professores a vontade em continuar os estudos em nível de pós-graduação. Por serem cursos que demandam uma carga horária maior para estudo, possibilitam reflexões que contribuem para o desenvolvimento profissional dos professores (CAPES, 2014C).

No caso de cursos ofertados na modalidade a distância, pesquisas apontam resultados satisfatórios com o uso de TICs, tanto no ensino, quanto na aprendizagem, evidenciando a formação de comunidades de aprendizagem, fator importante e promissor para haver desenvolvimento profissional.

Com relação aos programas Prolind e ao Procampo, conforme Relatório de Gestão do MEC (BRASIL. MEC, 2014b), eles são os responsáveis pelo desenvolvimento de, respectivamente, 26 e 45 licenciaturas (primeira ou segunda), apoiando as IPES na criação de cursos de licenciatura em Educação Indígena ou do Campo. Esses programas convergem em suas finalidades ao atendimento da inclusão e da diversidade cultural, (BRASIL. MEC, 2014b).

Charlot (2011, p.175), referindo-se à diversidade cultural e suas contradições, afirma que a educação, vista como prática de socialização, humanização e subjetivação, é marcada por contradições e que "o trabalho do professor não é resolver contradições, mas esclarecê-las e evidenciar as várias formas de legitimidade". No caso da criação dos programas de formação Prolind e Procampo, é possível reconhecer um investimento em políticas públicas de formação para que os professores trabalhem considerando a interculturalidade e atendendo o direito à diferença.

O Prolind, associado à proposição de curso de licenciatura indígena, segundo Pinto (2011), atendeu as expectativas dos alunos, considerando que o trabalho se pauta na interculturalidade, contribuindo para o debate do ensino superior voltado aos Povos Indígenas. No entanto, para Medeiros (2014), esses alunos ainda não conseguem ser 
agentes de transformação das práticas de ensino nas escolas da comunidade, o que indica necessidade de repensar o processo de formação.

Sobre o Procampo, pesquisas (BRAZ, 2014; SILVA, 2012; BARRADAS, 2014) indicam que a formações inicial e continuada dos professores não contemplam uma formação para o contexto rural, sendo ainda um desafio à diferenciação do significado das práticas pedagógicas na cidade/campo. Outros estudos (BENTES, 2014; SILVA, 2013) apontam dificuldades de ordem pedagógica, de infraestrutura no curso de licenciatura e que estaria distante a qualificação do professor com o perfil desejado. Mas, apesar disso, também são reconhecidos efeitos positivos na atuação dos educadores do campo e um ganho para a comunidade quanto à valorização da cultura de seus sujeitos. Por ter, esse programa, tempo e fomento limitados, algumas IPES já estão firmando o compromisso de implentaram o curso de licenciatura em Educação do Campo, como curso regular.

Sobre o Observatório da Educação (Obeduc), consideram-se informações disponibilizadas no site da Capes/DEB. O programa envolve pesquisa em educação e tem por finalidade a articulação entre pós-graduação, licenciaturas e escolas de educação básica, com fortalecimento da produção acadêmica e incentivo à formação de profissionais em nível de pós-graduação stricto sensu, em Educação ou Ensino, sendo que os participantes - alunos de cursos de licenciatura, alunos de pós-graduação e professores da educação básica - recebem bolsas de estudos. De acordo com o Relatório de Gestão DEB 2009-2014, foram concedidas 977 bolsas de mestrado ou doutorado para professores da educação básica que cursavam 212 programas de pós-graduação vigentes no período (CAPES, 2013C, 2015).

Conforme dados de 2014, além dos programas citados, foram implementadas, em todas as regiões do país, políticas de formação inicial e continuada de professores, cujos programas - Prodocência, com 74 projetos (CAPES, 2013e, 2014b), Novos Talentos, com 85 projetos (CAPES, 2014C), e Life, com 126 projetos (CAPES, 2014a) - tinham a finalidade de dar suporte (material) ao estudo e desenvolvimento de novas metodologias e tecnologias de ensino e de aprendizagem, visando ao aperfeiçoamento dos professores da educação básica e das IPES. No caso do Life, por exemplo, foram equipados laboratórios para a formação de professores multidisciplinares nas IPES para a realização de ações de formação docente. 
Quanto às finalidades dos programas de formação continuada, pode-se dizer que todos anunciam ter como objetivo a melhoria do processo de ensino e de aprendizagem em todos os níveis de ensino, principalmente da educação básica (educação infantil, em diferentes áreas do Ensino Fundamental e do Ensino Médio), mas também do ensino superior, ao contar com professores das universidades para atuar como coordenadores, orientadores, supervisores ou tutores nos ditos programas executados.

No Brasil, os programas de formação continuada são semelhantes ao que Formosinho (2009, p. 226) se refere como formação contínua em Portugal, pois,

as instituições formadoras são escolas, centros de professores, e universidades; os agentes de formação são formadores peritos e formadores pares, formadores externos e formadores internos; as modalidades são cursos, oficinas, seminários, supervisão, circulo de estudos; e os aspectos organizacionais demandam um processo de decisão, acreditação das ações, financiamento e espaço e tempo para formação.

Elencamos, no Quadro 1, dez programas de formação continuada: Rede Nacional, Pró-Infantil, Proinfo Integrado, Portal dos Professores, Prouca e UCA, Gestar II, Educação Especial, Pró- Letramento, Pnaic e Pnem. Com exceção do Pró-Infantil, os demais oferecem cursos de formação em parceria com universidades, sendo a maioria deles cursos de aperfeiçoamento para professores da educação básica que estão em exercício. A seguir, dá-se destaque aos programas Pró-Infantil, Proinfo Integrado, Prouca, Gestar II, Educação Especial, Pró-Letramento, Pnaic e Pnem, em função da abrangência dos programas, com atenção aos que já foram objeto de pesquisa nesses últimos anos.

O Programa Pró-Infantil foi ofertado entre 2005 e 2011, para 15.646 professores da educação infantil e refere-se a um curso de nível médio na modalidade Normal, com duração de dois anos. Quanto aos efeitos do curso, duas pesquisas (SILVA, 2014a; LAMARE, 2011) apontam que não pode ser entendido como formação acadêmica devido a sua brevidade (dois anos), descontinuidade e rupturas no processo de construção do conhecimento. No entanto, concluem que, ao procurar transformar professores leigos, que não se viam como protagonistas de uma fase tão importante quanto a infância, o 
Pró-Infantil teve o seu mérito, porém destacam ser necessária uma política educacional permanente para a formação de professores deste nível de ensino.

O Programa Nacional de Formação Continuada em Tecnologia Educacional (Proinfo Integrado) integra o Projeto UCA e Programa Um Computador por Aluno (Prouca). Com finalidades de capacitação dos profissionais da educação para o uso das TICS, o Proinfo promoveu cursos de curta duração, tendo em média, entre $120 \mathrm{~h}$ e $300 \mathrm{~h}$.

O Proinfo Integrado, de 2007 a 2013, certificou cerca de 300 mil profissionais da educação básica e distribuiu computadores para 22 mil laboratórios de informática, em escolas urbanas e rurais do país, promovendo a formação digital de professores e alunos (BRASIL, MEC, 2013d).

O Prouca, fomentado pelo FNDE, concedeu 6.979 bolsas em 2012 e previu e distribuição de cerca de 50 mil laptops (BRASIL. MEC, 2013d), que possibilitariam o uso das tecnologias digitais para a melhoria do ensino. No entanto, o incentivo e desenvolvimento de autoria e de práticas inovadoras, uma das principais finalidades do programa, não foi alcançado, em função das precárias condições de infraestrutura das escolas, da sobrecarga do trabalho docente, da falta de suporte técnico, de dificuldades de acessar a internet, da baixa inclusão digital e da descontinuidade na formação dos professores (SILVA, 2014b; BRUZZI, 2013), especialmente considerando que esta formação deve ultrapassar o instrumentalismo (BURLAMAKI, 2014).

Outro estudo sobre os programas Proinfo Integrado e Prouca (SILVA, 2014b), evidenciou o descompasso entre o discurso dos documentos oficiais e as práticas efetivas, sendo que a problemática nos efeitos dos programas para a educação básica se resumiria no distanciamento entre o planejado e o executado. Sobre o alcance de finalidades do Proinfo, este seria justificado em função de que o uso das TICs enriqueceria a formação de professores e permitiria recriar a prática docente (SILVA NETO, 2014), ou que haveria boas influências na prática docente daqueles que frequentassem o curso (FREIRE, 2013). No entanto, essas políticas foram bastante criticadas por sua ação instrumental de capacitação e por considerar que estariam focalizando o uso das TICs para responder a uma demanda do setor produtivo, mas não para pensar e estruturar práticas pedagógicas (FOIS, 2014). 
Considera-se, ainda hoje, que o uso das TICs é um desafio para professores e gestores (FLORES, 2014), tendo sido um dos maiores entraves para o aproveitamento dos profissionais a oferta do curso fora do horário de trabalho, considerando a sua sobrecarga de atividades (FREIRE, 2013).

Prata (2005) destaca que a relevância social do programa depende do contexto em que estão inseridos os professores e afirma, também, que o fato de o Proinfo obedecer aos moldes de programas do Banco Mundial faz com que o curso seja feito de forma aligeirada para baratear os seus custos. Para melhoria dos resultados com relação à utilização das TICs, avalia-se que haveria necessidade de mudança estrutural e curricular nas escolas (SCHNELL, 2009), o que exigiria melhorar os investimentos na formação pedagógica dos professores no programa Proinfo.

Resultados de pesquisas sobre esse tipo de programa de capacitação mostram serem cursos com carga horária pré-definida, de curta duração e sem previsão de continuidade, características que dificultam o alcance dos efeitos almejados. Acredita-se que a duração dos cursos tem influência nos efeitos da formação de professores, uma vez que as mudanças, mesmo as pretendidas, por exemplo, durante uma intervenção didática, não são imediatas. "[...] Por isso é nociva a descontinuidade de políticas e ações que interrompem processos que começam a tomar sentido e a se consolidar para as pessoas envolvidas com a educação escolar" (GATTI e BARRETO, 2009, p. 229). Com esse mesmo entendimento, segundo Formosinho (2009), os cursos de curta duração em Portugal também passaram a ser desacreditados.

Outro programa, no âmbito das políticas de formação, o Gestar II, tinha como ação um curso com carga horária de $300 \mathrm{~h}$ e teve por finalidade a melhoria do processo ensino e aprendizagem dos alunos, contribuindo para o aperfeiçoamento e autonomia do professor na sua prática pedagógica. Foi oferecido, entre 2008 e 2013, a cerca de 170 mil professores dos anos finais do Ensino Fundamental, das áreas de Português e Matemática. Estudos sobre esse programa apontam como efeitos esperados do curso, a mudança de metodologia, de materiais utilizados e melhor desempenho do professor em sala de aula (FONTES, 2014; ROCHA, 2011; MACEDO, 2006).

No entanto, salientam que nem sempre a formação dos professores significa melhoria na qualidade no ensino e aprendizagem na escola (FONTES, 2014), sendo 
apontados limites, caso os professores não entendam o significado do programa para a sua formação, o que seria um empecilho para a promoção do seu desenvolvimento pessoal e profissional (SILVA FILHO, 2013). A razão para essa dificuldade de o programa ter sentido para os professores, estaria relacionada, de acordo com Ribeiro (2014), ao contexto neoliberalista e influência do Banco Mundial para o planejamento e desenvolvimento do curso, uma vez que o desenvolvimento da autonomia dos professores se resumiu em subjetivar e disciplinar o professor pelas regras do programa (SILVA, 2012). Para Bressanin (2012), programas como o Gestar II representam políticas que sustentam formações continuadas de professores, atribuindo a eles o fracasso escolar.

Com relação ao Programa de Formação Continuada de Professores na Educação Especial, entre os anos de 2007 a 2013, foi oferecido um curso a 45 mil professores, visando capacitá-los para atuarem em salas de recursos multifuncionais e em classes comuns do ensino regular. Sobre seus efeitos na educação escolar, Valadão (2013) ressalta que a formação de professores para trabalhar com Educação Especial nas escolas regulares é muito recente, não sendo conhecidos ainda os resultados desta formação. Além disso, considera que seria necessário haver, na escola, melhores condições de trabalho aos professores para que pudessem realizar reuniões de múltiplos profissionais com as famílias. Também é importante discutir as limitações de ação do programa envolvendo o Atendimento Educacional Especializado (AEE) que, para Buiatti (2013), apresenta problemas para o efetivo trabalho, estando entre esses, o espaço físico, a falta de materiais e as dificuldades de interlocução entre classe comum e o AEE.

Semelhante ao Programa Gestar II, o Programa Pró- Letramento objetiva colaborar para a melhoria do processo ensino e aprendizagem, nos anos iniciais do ensino fundamental, em Lingua Portuguesa e Matemática. Sendo também considerado de curta duração, característica que dificulta espaço e tempo de reflexão sobre a teoria e a prática, o Pró- Letramento ofertou, entre 2005 e 2012, cerca de seis mil bolsas a professores cursistas, sendo que, a partir de 2008, passou a estar vinculado à Provinha Brasil (BRASIL. MEC, 2013d). O Pró- Letramento teve início com o programa Praler (iniciado em 2001) e, a partir de 2012, foi substituído pelo programa Pnaic. 
O Pró- Letramento sofreu críticas de que as medidas adotadas pelo programa não seriam suficientes para promover a efetiva qualidade da educação e que não discutia questões importantes, como a valorização dos professores e a infraestrutura das escolas (ALFERE, 2009). No entanto, houve também reconhecimento de que o programa teria possibilitado aos professores a capacidade de ressignificar os conteúdos didáticos do programa no contexto da realidade de suas salas de aulas (SÃO JOSÉ, 2012; CROZATTO, 2011).

Como já dito, o Programa Nacional para Alfabetização na Idade Certa (Pnaic) deu continuidade ao Pró- Letramento. Tem como finalidade a melhoria da qualidade de aprendizagem de leitura/escrita e matemática nos anos/séries iniciais do ensino fundamental, acrescido do debate acerca dos direitos de aprendizagem das crianças, indicando a possibilidade de o curso significar, além de atualização e aperfeiçoamento, um espaço de interação e reflexão dentro da escola.

O Pnaic, entre os anos de 2013 e 2015, ofereceu ações de formação para 317 mil professores alfabetizadores da educação básica, sendo distribuídas 2.507.219 bolsas de estudo, fomentadas pelo Fundo Nacional de Desenvolvimento da Educação (FNDE) (BRASIL, 2013; BRASIL. MEC, 2015b). Pesquisas sobre o Pnaic apontam que suas ações teriam possibilitado um novo olhar dos professores para e sobre a alfabetização, o que incluiria comprometimento e preocupação com o ato de aprender e ensinar de maneira reflexiva e inovadora (TEDESCO, 2015). Outra pesquisa afirma que esta formação oportunizaria aos professores a atualização de conhecimentos que estão em constante transformação na sociedade (SALOMÃO, 2014).

Monteiro (2014), em estudo sobre o Pnaic, procurou verificar as marcas identitárias dos professores alfabetizadores e ver como seriam afetadas pela formação continuada, considerando que o espaço da formação é útil para possibilitar interações, tanto com formadores quanto com seus pares. Conclui que a formação afeta as marcas identitárias dos professores, principalmente com relação à alteridade, ou seja, na relação com o outro, por conhecer, respeitar, compreender e aprender com a diferença (MONTEIRO, 2014).

Em modelo semelhante ao Pnaic, o Pacto Nacional pelo Fortalecimento do Ensino Médio Nacional (Pnem), é um programa de formação continuada para professores e 
coordenadores pedagógicos que atuam no Ensino Médio não profissionalizante nas áreas rurais e urbanas. No ano de 2013, houve a adesão dos estados das regiões brasileiras ao programa, cujas ações, com duração de um ano, iniciaram em 2014, com previsão de oferta de cerca de 450 mil bolsas de estudo para professores e coordenadores pedagógicos que participassem da formação (BRASIL. MEC, 2013C).

Ao apresentar as ações realizadas pelos diferentes programas de formação continuada, procurou-se observar a relação dessas com o desenvolvimento profissional de professores. Nesse sentido, de acordo com Imbernón (2009), entende-se que em muitos desses programas não são respeitadas as singularidades e as necessidades do contexto escolar em que esses professores se inserem, o que dificulta o desenvolvimento da autonomia para a realização de intervenções diretas aos professores. Além disso, deixa-se de considerar os projetos desenvolvidos nas escolas, sem que os professores reconheçam uma formação que atenda suas necessidades.

Ainda, conforme Imbernón (2009), as propostas de formação docente deveriam ser analisadas considerando sua continuidade/descontinuidade, a infraestrutura e carga horária, mas principalmente o modo como são relacionadas teoria e prática, a criação de espaços de reflexão sobre a prática e de comunidades de aprendizagem, para que haja o desenvolvimento profissional dos professores. Nesta direção, também Nóvoa (2009, p. 20) afirma que, a formação de professores em serviço deve ser acompanhada de reflexão pelo coletivo, pois seria "esta reflexão colectiva que dá sentido ao seu desenvolvimento profissional", e não apenas por um professor que inova ou propõe mudanças por iniciativa pessoal.

Gatti e Barreto (2009, p. 196), ao apresentarem o cenário da formação continuada de professores, na década de 80, afirmam que seja qual for a finalidade, "atualização ou complementação de conhecimentos, ou para preparar a implementação de uma reforma educativa, não produziram os efeitos esperados". Ao examinar o leque de programas implementados nos últimos 12 anos, percebe-se que, de modo semelhante ao apontado pelas autoras, a formação em massa, a brevidade dos cursos, os limites dos recursos financeiros, a dificuldade em fornecer instrumentos e apoio necessários nesses espaços de formação impossibilitam ou dificultam as mudanças esperadas pelas políticas de formação inicial e continuada de professores. 
Esses, entre outros, são fatores importantes que devem ser considerados na realização de práticas de formação, pois especialmente o modelo de programa que capacita alguns professores que, por sua vez, capacitam outros colegas, pode não promover o seu desenvolvimento profissional. O modelo de capacitação em “cascata” é caracterizado pelas autoras do seguinte modo:

[...] um primeiro grupo de profissionais é capacitado e transforma-se em capacitador de um novo grupo que por sua vez capacita um grupo seguinte. Mediante esse procedimento, que geralmente percorre os diferentes escalões da administração dos extensos sistemas de ensino, corpo técnico-pedagógico, supervisores regionais, professores especialistas, embora permita envolver um contingente profissional bastante expressivo em termos numéricos, tem se mostrado pouco efetivo quando se trata de difundir os fundamentos de uma reforma em suas nuances, profundidade e implicações. (GATTI; BARRETO, 2009, p. 197)

Esse modelo é reconhecido em alguns programas de formação que examinados, em especial no Pnaic e no Pnem. São programas relativamente novos, ainda com poucos resultados de pesquisa, mas caracterizam políticas importantes, especialmente em função do número de professores atingidos. Essa abrangência, certamente, tem a ver com o efeito "cascata" da capacitação, na qual os professores das escolas recebiam formação do orientador de estudos, este recebia formação do formador regional que, por sua vez, era formado pelos formadores das IPES. Mas, como vimos na literatura, esse modelo sofre críticas, especialmente pela ideia de formação em massa.

\section{Considerações finais}

Apresentou-se um estudo sobre os programas de formação inicial e continuada de professores no Brasil, no período de 2003 a 2015, visando construir um panorama do contexto brasileiro de produção de políticas públicas para a formação de professores. Teve-se um olhar mais atento para a formação continuada na perspectiva de compreensão do papel dos cursos e de suas ações para o desenvolvimento profissional dos professores.

Quanto aos resultados das ações propostas pelos programas de formação continuada, por meio de cursos de aperfeiçoamento e capacitação, de curta duração, 
considera-se que as ações adotadas podem não ser suficientes para promover melhoria de qualidade de ensino e aprendizagem dos alunos, mas possibilitam ressignificar o desempenho dos professores em sala de aula com relação às metodologias e conteúdos didáticos. No entanto, isso não quer dizer que possibilite um espaço e tempo de reflexão para a construção coletiva de novos significados da relação entre teoria e prática e, principalmente, espaços para a produção de comunidades de aprendizagem, sem os quais diminui a potência para que se consiga promover o desenvolvimento profissional dos professores.

\section{Referências}

ALFERE, Maria Aparecida. Formação continuada de professores alfabetizadores: uma análise crítica do Programa Pró-Letramento. 2009. 159f. Dissertação (Mestrado em Educação) - Universidade Federal de Ponta Grossa, Programa de Pós Graduação em Educação, Ponta Grossa, 2009.

AMORIM, Ivonete Barreto de. Entre casulo e asa: diálogos e movimentos dos selves de professoras estudantes no contexto da formação no Parfor. 2013. $211 \mathrm{f}$. Tese (Doutorado) - Universidade Católica de Salvador, Programa de Pós-Graduação em Família na Sociedade Contemporânea, Salvador, 2013.

BANCO MUNDIAL. Prioridades y estrategias para la educación: examen del Banco Mundial. N.W. ; Washington, D.C: Banco Internacional de Reconstrucción y Fomento, 1996. Disponível em: < http://www-

wds.worldbank.org/external/default/WDSContentServer/IW3P/IB/2005/06/13/000160016_ 20050613172136/Rendered/PDF/14948010spanish.pdf>. Acesso em: 10 set. 2015. 
BARRADAS, Cleane de Jesus Costa. Educação do campo formação continuada de professores do Programa Escola Ativa em Buriti (MA). 2013.199f. Dissertação (Mestrado) - Universidade de Taubaté, Programa de Pós Graduação em Desenvolvimento Humano: Formação, Políticas e Práticas Sociais, Taubaté, 2013.

BENTES, Elane do Socorro da Silva. Os desafios da licenciatura em educação do campo no IFPA: Campus de Abaetetuba/PA. 2014. 127 f. Dissertação (Mestrado) - Universidade Federal do Pará, Instituto de Ciências Sociais Aplicadas, Programa de Pós-Graduação em Serviço Social, Belém, 2014.

BRANCO, Juliana Cordeiro Sore. A formação de professores a distância no sistema UAB: análise de duas experiências em Minas Gerais. 2014. 26of. Tese (Doutorado em Educação) - Universidade Federal de Minas Gerais, Programa de Pós Graduação em Educação: Conhecimento e Inclusão Social, Belo Horizonte-MG, 2014.

BRASIL. Decreto $n^{\circ}$ 6755, de 29 de janeiro de 2009. Institui a Política Nacional de Formação de Profissionais do Magistério da Educação Básica, disciplina a atuação da Coordenação de Aperfeiçoamento de Pessoal de Nível Superior- CAPES no fomento a programas de formação inicial e continuada, e dá outras providências. Brasília, 2009, Disponível em:< http://www.planalto.gov.br/ccivil_03/_ato20072010/2009/decreto/d6755.htm>. Acesso em: 13 jul.2015.

BRASIL. Lei $\mathbf{n}^{\circ}$ 12801, de 24 de abril de 2013. Dispõe sobre o apoio técnico e financeiro da União aos entes federados no âmbito do Pacto Nacional pela Alfabetização na Idade Certa e altera as Leis $n^{0 s} 5.537$, de 21 de novembro de 1968, 8.405, de 9 de janeiro de 1992, e 10.260, de 12 de julho de 2001. 2013. Disponível em:

<http://www.planalto.gov.br/ccivil_03/_Ato2011-2014/2013/Lei/L12801.htm>. Acesso em: 17 dez. 2015

BRASIL. Plano Nacional de Educação 2014-2024: Lei no 13.005, de 25 de junho de 2014. Aprova o Plano Nacional de Educação (PNE) e dá outras providências. - 2. ed. Brasília: Câmara dos Deputados: Edições Câmara, 2014. (Série legislação; n. 193).

BRASIL. Ministério da Educação. Política Nacional de Educação Especial na Perspectiva da Educação Inclusiva. Brasília, 2008. Disponível em:

<http://portal.mec.gov.br/arquivos/pdf/politicaeducespecial.pdf>. Acesso em: 18 abr.2016.

BRASIL. Ministério da Educação. Diretrizes Curriculares Nacionais da Educação Básica. Brasília. 2013a. Disponível em:

<http://portal.mec.gov.br/index.php?option=com_docman\&view=download\&alias=15548d-c-n-educacao-basica-nova-pdf\&ltemid=30192>. Acesso em: 10 nov. 2014.

BRASIL. Ministério da Educação. Diretrizes Curriculares Nacionais Gerais para a Educação Básica: diversidade e inclusão. Brasília. 2013b. Disponível em: <http://portal.mec.gov.br/index.php?option=com_docman\&view=download\&alias=17212diretrizes-curriculares-nacionais-para-educacao-basica-diversidade-e-inclusao2013\&category_slug=marco-2015-pdf\&ltemid=30192>. Acesso em: 13 out.2015. 
BRASIL. Ministério da Educação. Portaria n 1140, de 22 de novembro de 2013. Institui o Pacto Nacional pelo Fortalecimento do Ensino Médio e define suas diretrizes gerais, forma, condições e critérios para a concessão de bolsas de estudo e pesquisa no âmbito do ensino médio público, nas redes estaduais e distrital de educação. 2013c. Disponível em:

<http://portal.mec.gov.br/index.php?option=com_docman\&view=download\&alias=15069pacto-dou-1-2\&category_slug=janeiro-2014-pdf\&ltemid=30192>. Acesso m: 13 nov. 2014.

BRASIL. Ministério da Educação. Relatório de Gestão MEC/SEB exercício 2012. Brasília, 2013d. Disponível em:

<http://portal.mec.gov.br/index.php?option=com_docman\&view=download\&alias=14255relatorio-gestao-da-seb-exercicio-2012-pdf\&Itemid=30192>. Acesso em: 13 jan. 2016.

BRASIL. Ministério da Educação. Documento orientador 2014 do Pacto Nacional pela

Alfabetização na Idade Certa. Brasília, 2014a. Disponível em:

<http://pacto.mec.gov.br/images/pdf/Formacao/documento_orientador_2014_versao_sit e.pdf>. Acesso em: 12 jul. 2014.

BRASIL. Ministério da Educação. Relatório de Gestão MEC 2014. Brasília, 2014b. Disponível em: <http://portal.mec.gov.br/secretaria-de-educacao-continuada-alfabetizacaodiversidade-e-inclusao/programas-e-acoes>. Acesso em: 10 jan. 2016.

BRASIL. Ministério da Educação. Relatório de Gestão Consolidado 2014 MEC. Brasília, 2014C. Disponível em:

<http://portal.mec.gov.br/index.php?option=com_docman\&view=download\&alias=15992relatorio-gestao-exercicio-2013-seb-pdf\&ltemid=30192>. Acesso em: 15 jan. 2016.

BRASIL. Ministério da Educação. Pacto nacional pela alfabetização na idade certa:

Documento orientador das ações de formação continuada de professores alfabetizadores em 2015. Brasília, 2015a. Disponível em:

<http://pacto.mec.gov.br/images/pdf/Formacao/documento_orientador_2015_versao_sit e.pdf.> Acesso em: 07 nov. 2015.

BRASIL. Ministério da Educação. Programas do MEC voltados a formação de professores, Brasilia, 2015b. Disponível em:

<http://portal.mec.gov.br/component/content/article?id=15944>. Acesso em: 11 jan. 2016.

BRASIL. Ministério da Educação. Conselho Nacional de Educação. Resolução $\mathrm{CNE} / \mathrm{CP} \mathbf{n}^{\circ} \mathbf{2}$, de $1^{\circ}$ de julho de 2015: Define as Diretrizes Curriculares Nacionais para a formação inicial em nível superior (cursos de licenciatura, cursos de formação pedagógica para graduados e cursos de segunda licenciatura) e para a formação continuada. Brasília, 2015C. Disponível em: <http://portal.mec.gov.br/secretaria-de-regulacao-e-supervisao-daeducacao-superior-seres/323-secretarias-112877938/orgaos-vinculados-82187207/21028resolucoes-do-conselho-pleno-2015>. Acesso em: 12 jul. 2015. 
BRAZ, Simone Guimarães. Educação do campo e professores das escolas rurais: as representações sociais sobre competência. 2014. 16of. Dissertação (Mestrado em Educação) - Universidade de Taubaté, Programa de Pós Graduação de Educação, Taubaté, 2014.

BRESSANIN, Joelma Aparecida. Políticas de formação continuada de professores em Mato Grosso: uma análise Discursiva do Programa Gestar. 2012. 248f. Tese (Doutorado em Educação) - Universidade Federal de Campinas, Programa de Pós Graduação em Educação, Campinas-SP, 2012.

BRUZZI, Demerval Guilarducci. Competências docentes no aprender a ensinar com o laptop educacional: programa um computador por aluno (UCA) 2010/2011. 2013. 213f. Dissertação (Mestrado em Educação) - Universidade Católica de Brasília Programa de PósGraduação em Educação, Brasília-DF, 2013.

BUIATTI, Viviane Prado. Atendimento educacional especializado: dimensão política, formação docente e concepções dos profissionais. 2013. $245 \mathrm{fl}$. Tese (Doutorado em Educação) - Universidade Federal de Uberlândia, Faculdade de Educação Programa de Pós Graduação em Educação, Uberlândia-MG, 2013.

BURLAMAKI, Akynara Aglae Rodrigues Santos da Silva. Formação de professores, saberes, reflexividade e apropriação da cultura digital no projeto um computador por aluno (UCA). 2014. 60 f. Tese (Doutorado em Educação) - Universidade Federal do Rio Grande do Norte, Programa de Pós Graduação em Educação, Natal, 2014.

CHARLOT, Bernard. Da relação com o saber às práticas educativas. $1^{\text {a }}$ ed. São Paulo: Cortez. 2013.

COORDENADORIA NACIONAL DE APERFEIÇOAMENO DE PESSOAL DE NÍVEL SUPERIOR. Edital Pibid Diversidade. Brasília, 2013a. Disponível em:

<http://www.capes.gov.br/images/stories/download/editais/Edital_066_2013_PibidDiversidade-692013.pdf >. Acesso em: 13 jan. 2016

COORDENADORIA NACIONAL DE APERFEIÇOAMENO DE PESSOAL DE NÍVEL SUPERIOR Relatório da Secadi. Brasília, 2013b. Disponível em:

<http://webcache.googleusercontent.com/search?q=cache:c6EbRIVFA24J:www19.senado .gov.br/sdleg-getter/public/getDocument\%3Fdocverid\%3Dc93bb1ab-484f-4df7-967c1b5163876699\%3B1.0+\&cd=3\&hl=pt-BR\&ct=clnk\&gl=br>. Acesso em: 10 mar. 2016.

COORDENADORIA NACIONAL DE APERFEIÇOAMENO DE PESSOAL DE NÍVEL SUPERIOR. Relatório de Gestão Observatório da Educação 2009-2013. DEB/ Capes. Brasília, 2013C. Disponível em:< http://www.capes.gov.br/images/stories/download/bolsas/1892014relatorios-OBEDUC-E-OBEDUC-INDIGENA.pdf>. Acesso em: 13 jan. 2016.

COORDENADORIA NACIONAL DE APERFEIÇOAMENO DE PESSOAL DE NÍVEL SUPERIOR. Edital Pibid n 61/2013. Brasília, 2013d. Disponível em: 
<http://www.capes.gov.br/images/stories/download/editais/resultados/Edital_61_2013_PIBI D_ResultadoFinal.pdf >. Acesso em: 13 jan. 2016.

COORDENADORIA NACIONAL DE APERFEIÇOAMENO DE PESSOAL DE NÍVEL SUPERIOR. Edital 19/2013- Programa Prodocência. Brasília, 2013e. Disponível em:

<http://www.capes.gov.br/educacao-basica/prodocencia>. Acesso em: 12 jan. 2016.

COORDENADORIA NACIONAL DE APERFEIÇOAMENO DE PESSOAL DE NÍVEL SUPERIOR. Relatório de Gestão 2009 - 2013 - Programa Life. Brasília, 2014a. Disponível em: <http://www.capes.gov.br/images/stories/download/bolsas/1892014-relatorio-LIFE.pdf>. Acesso em: 11 nov. 2015.

COORDENADORIA NACIONAL DE APERFEIÇOAMENO DE PESSOAL DE NÍVEL SUPERIOR. Relatório de Gestão 2009 - 2013 - Programa Prodocência. Brasília, 2014b. Disponível em: <http://www.capes.gov.br/educacao-basica/prodocencia>. Acesso em: 23 jan. 2016.

COORDENADORIA NACIONAL DE APERFEIÇOAMENO DE PESSOAL DE NÍVEL SUPERIOR. Relatório de Gestão - 2014 DEB/Capes. Brasília, 2014C. Disponível em: <http://www.capes.gov.br/images/stories/download/Contas_Publicas/2014_Relatorio_de_ Gestao_CAPES.pdf>. Acesso em: 12 jan. 2016.

COORDENADORIA NACIONAL DE APERFEIÇOAMENO DE PESSOAL DE NÍVEL SUPERIOR. Relatório de Gestão DEB 2009-2014. Brasília, 2015. Disponível em: <http://www.capes.gov.br/images/stories/download/bolsas/20150818_DEB-relatorio-degestao-vol-1-com-anexos.pdf >. Acesso em: 10 jan. 2016.

CORREA, Magda Rosane Nunes. Um olhar "pibidiano" sobre o desenvolvimento profissional de professores supervisores do PIBID/UFPel. 2014. $160 \mathrm{f}$. Dissertação (Mestrado em Ensino de Ciências e Matemática) - Universidade Federal de Pelotas, Programa de Pós Graduação em Ensino de Ciências e Matemática, Pelotas-RS, 2014.

CROZATTO, Rosa Venice Curti. Formação continuada Pró- Letramento Alfabetização e linguagem e a prática do professor: um estudo de caso. 2011, 153f. Dissertação (Mestrado em Educação) - Universidade Estadual de Londrina. Centro de Educação, Comunicação e Artes. Programa de Pós-Graduação em Educação, Londrina- PR, 2011.

DEIMLING, Natalia Neves Macedo. Programa institucional de bolsa de iniciação à docência: contribuições, limites e desafios para a formação docente. 2014.165f. Tese (Doutorado em Educação) - Universidade Federal de São Carlos, Faculdade de Educação Programa de Pós-Graduação em Educação, São Carlos-SP, 2014.

FLORES, Vania de Fátima. Um olhar sobre a implantação do Proinfo em escolas municipais de Minas Gerais. 2014. 175f. Dissertação (Mestrado Profissional em Educação) - Universidade Federal de Lavras, Departamento de Educação, Programa de PósGraduação em Educação, Lavras-MG, 2014. 
FOIS, Naira Fonseca. Proinfo em Nova Iguaçu: tecnologia educacional e formação cultural ou informática educativa e semiformação. 2014. 16of. Dissertação (Mestrado em Educação) - Universidade Estadual do Rio de Janeiro, Programa de Pós-Graduação em Educação, Cultura e Comunicação em Periferias Urbanas, Rio de Janeiro-RJ, 2014.

FONTES, Anderson Rios. Formação continuada de professores da educação básica: um estudo sobre o programa Gestar no estado da Bahia. 2014. 146f. Dissertação (Mestrado em Educação) - Universidade Federal da Bahia, Programa de Pós-Graduação em Educação Salvador-BA, 2014.

FORMOSINHO, João Manuel. (Coord). Formação de professores: aprendizagem profissional e acção docente. Porto: Porto Editora, 2009.

FREIRE, Wilma Rodrigues. Avaliação do Programa Nacional de Tecnologia Educacional Proinfo na perspectiva da forrmação docente em Frotaleza. 2013. 155f. Dissertação (Mestrado em Educação) - Universidade Federal do Ceará, Programa de Pós-Graduação em Avaliação de Políticas Públicas, Fortaleza-CE, 2013.

GATTI, Bernadete Angelina. Análise das políticas públicas para formação continuada no Brasil, na última década. Revista Brasileira de Educação. v. 13, n. 37, jan./abr. 2008.

GATTI, Bernadete Angelina; BARRETO, Elba de Sá André (Coord.). Professores do Brasil: impasses e desafios. Brasília: UNESCO, 2009. 294 p.

IMBERNÓN, Francisco. Formação permanente do professorado: novas tendências. São Paulo: Cortez Editora, 2009.

KUENZER, Acacia. A Formação de Professores para o Ensino Médio: Velhos Problemas, Novos Desafios. Educação \& Sociedade. Campinas, v. 32, n. 116, p. 667-688, jul./set. 2011. Disponível em:< http://www.scielo.br/pdf/es/v32n116/a04v32n116.pdf>. Acesso em: 2 nov. 2015.

LAMARE, Flavia de Figueiredo. Avanços e contradições nas políticas de formação de professores no Brasil contemporâneo: o caso do Proinfantil. 2011. 188 f. Dissertação (Mestrado Profissional em Educação Profissional em Saúde) - Fundação Osvado Cruz, Escola Politécnica de Saúde Joaquim Venâncio, Rio de Janeiro-RJ, 2011.

MACEDO. Valcinete. Pepino. Política de formação continuada de professores: Cenários, diretrizes e práticas. 2006. 228 f. Dissertação (Mestrado em Educação) - Universidade Federal do Rio Grande do Norte, Natal, 2006.

MARTELET, Michele. O Programa de Bolsa de Iniciação à Docência (PIBID) e a qualidade para a formação continuada de professores. 2015, 188f. Dissertação (Mestrado em Educação). Pontifícia Universidade Católica do Rio Grande do Sul, Porto Alegre-RS, 2015.

MARTINS, Selma Leila Bergo. Aprendizagem da docência em experiências de educação a distância: implicações para a prática docente presencial. 2015. 110f. Dissertação (Mestrado 
em Educação) - Universidade Federal de São Carlos, Programa de Pós Graduação em Educação, São Carlos-SP, 2015.

MEDEIROS, Laura Maria Brito. Licenciatura intercultural indígena no Centro Acadêmico do Agreste da UFPE: uma visão do egresso do curso 2009-2012. 2014. 120f. Dissertação (Mestrado em Gestão Pública) - Universidade Federal de Pernambuco Programa de Pós Graduação em Gestão Pública para Desenvolvimento do Nordeste, Recife-PE, 2014.

MONTEIRO. Fernanda Izidro. Professor alfabetizador: identidades, discursos e formação continuada. 2014. 135f. Dissertação (Mestrado em Educação) - Universidade Federal do Rio de Janeiro, Programa de Pós Graduação em Educação, Rio de Janeiro-RJ, 2014.

NÓVOA, Antonio. Professores: imagens do futuro presente. Lisboa: EDUCA. 2009 PINTO, Fabiana de Freitas. Licenciatura específica para formação de professores indígenas/turma mura: um balanço dos dois primeiros anos do curso à luz das expectativas dos alunos. 2011. 142 f. Dissertação (Mestrado em Educação) - Universidade Federal do Amazonas, Manaus-AM, 2011.

PRATA. Carmen Lucia. Gestão democrática e tecnologias da informática na educação básica: O Prolnfo no Espírito Santo. 2005. 219f. Dissertação (Mestrado em Educação) Universidade Federal do Rio Grande do Sul, Faculdade de Educação, Programa de Pós Graduação em Educação, Porto Alegre-RS, 2005.

RIBEIRO, Cleber Sardinha. Governança e formação de professores: a presença do Banco Mundial no Programa Gestar, 2014. 158f. Dissertação (Mestrado em Educação) -

Universidade Católica de Brasília, Programa de Pós Graduação em Educação, Brasília- DF, 2014.

ROCHA, Vanda Tereza Silva da. GESTAR II língua portuguesa: concepções de professores das escolas municipais de Fortaleza. 2011. 99f. Dissertação (Mestrado em Educação) Universidade Federal do Ceará, Faculdade de Educação, Programa de Pós-Graduação em Educação Brasileira, Fortaleza-CE, 2011.

ROPOLI, Edilene Aparecida. Formação de professores em atendimento educacional especializado (AEE): aspectos políticos, tecnológicos e metodológicos de um Curso de Formação de Professores na Modalidade a Distância. 2014. 249f. Tese (Doutorado em Educação) - Universidade Estadual de Campinas. Faculdade de Educação, Programa de Pós-Graduação em Educação, Campinas, SP, 2014.

SALOMÃO, Romy. A formação continuada de professores alfabetizadores: do próletramento ao PANAIC. 2014. 117f. Dissertação (Mestrado em Educação) - Universidade Estadual de Ponta Grossa, Programa de Pós Graduação em Educação. Ponta Grossa-PR, 2014.

SANTOS, Juliana Gomes dos. Narrativas de professoras de educação infantil: o processo de (re) significação da profissão a partir da formação em serviço. 2013. 189f. Dissertação 
(Mestrado em Educação) - Pontifícia Universidade Católica de Campinas, Programa de Pós Graduação em Educação, Campinas- SP, 2013.

SÃO JOSÉ, Lucimara de. Os efeitos do pró-letramento na formação das professoras alfabetizadoras do município de Conselheiro Lafaiete. 2012. 198f. Dissertação (Mestrado em Educação) - Universidade Federal de Minas Gerais, Programa de Pós Graduação Conhecimento e Inclusão Social em Educação, Belo Horizonte-MG, 2012.

SCHNELL, Roberta Fantin. Formação de professores para o uso das tecnologias digitais: um estudo junto aos núcleos de tecnologia educacional do Estado de Santa Catarina. 2009. 103f. Dissertação (Mestrado em Educação) - Universidade do Estado de Santa Catarina, Programa de Pós Graduação em Educação, Florianópolis-SC, 2009.

SILVA FILHO, Analdino Pinheiro. Formação continuada de professores de matemática: um estudo sobre a práxis docente no programa gestar II na Bahia. 2013. 134 f. Dissertação (Mestrado Acadêmico em Educação) - Universidade Estadual de Feira de Santana, Feira de Santana-BA, 2013.

SILVA NETO, Carlos Eugênio da. Competências em informação para inclusão digital: os professores da educação básica na sociedade em rede João Pessoa 2014. 2014. $93 f$. Dissertação (Mestrado em Informação, Conhecimento e Sociedade) - Universidade Federal da Paraíba, João Pessoa-PB, 2014.

SILVA, Livia Aparecida da. A disciplinarização do docente: uma análise discursiva do exercício disciplinador do programa gestar II. 2012. 200f. Dissertação (Mestrado em Linguística, Letras e Artes) - Universidade Federal de Goiás, Goiânia-GO, 2012.

SILVA, Luciene Fernanda da. Coordenadores de área do PIBID: um olhar sobre o desenvolvimento profissional 2015. 155f. Dissertação (Mestrado em Educação). Universidade de São Paulo, Instituto de Física, Química, Biociências e Faculdade de Educação, São Paulo-SP, 2015.

SILVA, Maria Divanete Sousa da. Concepções e práticas dos sujeitos envolvidos no curso de licenciatura em educação do campo no polo de Castanhal/PA. 2013. 120 f. Dissertação (Mestrado em Ciências Sociais) - Universidade Federal do Pará, Instituto de Ciências Sociais Aplicada Programa de Pós-Graduação em Serviço Social, Belém-PA, 2013.

SILVA, Polyana Aparecida Roberta da. Infância e educação infantil: programa de formação inicial para professores em exercício (2004 a 2010). 2014a. 214f. Tese (Doutorado em Educação) - Universidade Federal de Uberlândia Programa de PósGraduação em Educação, Uberlândia- MG, 2014.

SILVA. Welinton Baxto da. O uso do computador: prouca em seis escolas do Distrito Federal. 2014b. 133f. Dissertação (Mestrado em Educação) - Universidade de Brasília, Brasília, Faculdade de Educação, Programa de Pós-Graduação em Educação, 2014. 
SILVA, Sadi José Rodrigues da. A formação dos professores do campo: um estudo na Serra Catarinense. 2012. 149f. Dissertação (Mestrado em Educação) - Universidade Federal de Santa Catarina, Centro de Ciências da Educação, Programa de Pós-Graduação em Educação, Florianópolis-SC, 2012.

TEDESCO, Sirlei. Formação continuada de professores: experiências integradoras de políticas educacionais - Pnaic e ProUca- para alfabetização no ensino fundamental de uma escola pública. 2015. 134f. Dissertação (Mestrado em Educação) - Pontifícia Universidade Católica do Rio Grande do Sul, Porto Alegre-RS, 2015.

VALADÃO, Gabriela Tannús. Inclusão escolar e planejamento educacional individualizado: avaliação de um programa de formação continuada para educadores. São Carlos 2013. 248f. Dissertação (Mestrado em Educação Especial) - Universidade Federal de São Carlos Programa de Pós Graduação em Educação Especial. Centro de Educação e Ciências Humanas, São Carlos-SP, 2013. 